\title{
Diagnosis and characterization of canine parvovirus-2 affecting canines of South Gujarat, India
}

\author{
Kishan Kumar Sharma ${ }^{1}$, Irsadullakhan Habibullakhan Kalyani ${ }^{1}$, \\ Shailee Manishbhai Pandya ${ }^{1}$, Jignesh Alabhai Vala ${ }^{2}$
Navsari Agricultural University, College of Veterinary Science and Animal Husbandry, ${ }^{1}$ Department of Veterinary Microbiology, \\ ${ }^{2}$ Teaching Veterinary Clinical Complex Navsari, Gujarat, India
}

Received January 26, 2018

Accepted August 13, 2018

\begin{abstract}
The present study was carried out in the region of South Gujarat, India, to determine the prevalence and predisposing factors of canine parvovirus-2 (CPV-2) infection in acute gastroenteritis of pups. Further, haemagglutination (HA) test, enzyme linked immunosorbent assay (ELISA), polymerase chain reaction (PCR) and rapid immunochromatography test were compared for diagnosis and prevalent CPV-2 types were ascertained. A total of 73 diarrhoea samples were collected and out of those 32, 33 and 35 were found positive via HA, ELISA and PCR, respectively. In rapid test, 26/52 samples were found positive. Among different agegroups, $11 / 24$ and 13/21 animals were positive in pups aged 4-8 and 8-12 weeks, respectively. All but one (34/35) positive samples were from unvaccinated animals. Labrador was found to be the most susceptible breed $(\mathrm{n}=13)$ to infection. Considering PCR as the best test, $47.94 \%$ (35/73) prevalence of CPV was recorded. Among PCR positive samples, 3 and 32 belonged to type CPV-2a and CPV-2b, respectively. Type CPV-2c was not detected among the examined samples. Sequencing analysis of $9 / 10 \mathrm{CPV}-2 \mathrm{~b}$ isolates revealed single nucleotide polymorphism (SNP) (A-G) at position 4106 (alanine to threonine) and suggested the occurrence of mutant, new CPV-2b in this area. As other major pathogen canine coronavirus was detected in $7 / 38 \mathrm{CPV}$ negative samples. Conclusively, CPV-2 infection was detected in $47.97 \%$ cases of AGE of pups which warrants search for other pathogens in the diagnostic procedure. This work is among the few recent reports which depict the occurrence of a novel mutant (new CPV-2b) in India.
\end{abstract}

Canine coronavirus, new CPV-2b, polymerase chain reaction, sequencing, variant

Canine parvovirus-2 (CPV-2) is a causative agent of a highly contagious and often fatal acute gastroenteritis (AGE) in dogs. The involvement of other agents in AGE of pups, and the rapid morbidity and high mortality in CPV infection warrant an accurate and fast diagnosis of the disease (Decaro and Buonavoglia 2012). Clinical diagnosis is often indecisive and several other viral pathogens may produce similar symptoms in animals. At present laboratory diagnosis of CPV is carried out by haemagglutination (HA) test, antigen capture enzyme linked immunosorbent assay (ELISA), rapid immune chromatography test, virus isolation and polymerase chain reaction (PCR), and real time PCR. None of the tests is considered gold standard test and all the tests have their own advantages and limitations in different types of clinical settings (Desario et al. 2005; Decaro et al. 2010; Decaro et al. 2013; Decaro and Bounavogalia 2017).

The virus presumably emerged from the feline panleukopaenia virus as a host mutant in 1978 and spread quickly as a worldwide pandemic. In 1980s, two antigenic variants of CPV-2 emerged almost simultaneously and were termed as CPV-2a and CPV-2b (Parris h et al.1985). These variants are still considered predominant variants of CPV worldwide (Nandi and Kumar 2010). Recently, additional variations in VP2 protein of CPV-2a and $\mathrm{CPV}-2 \mathrm{~b}$ have been reported and these single amino acid mutants are designated as new 
CPV-2a and new CPV-2b, respectively (Martella et al. 2006). Currently, these mutants have replaced the prototype CPV-2a and CPV-2b and co-circulating with prototypes in many countries (Martella et al. 2005; Wu et al. 2015; Amrani et al. 2016; Filipov et al. 2016; Dowgier et al. 2017; Mira et al. 2018), including India (Nookala et al. 2016). In the year 2000, a new variant/type CPV-2c emerged in Italy with a change (Asp426Glu) in the VP2 protein (Buonavoglia et al. 2001). This mutant has also been reported from some parts of India (Nandi et al. 2010). As vaccination is the most effective and economical method to control CPV infection, the knowledge of prevalent types including the single amino acid mutants and their dynamics in the area requires constant updating.

Considering all these aspects of epidemiology and diagnosis, the present study was formulated to find the factual percentage of involvement of CPV-2 in AGE of pups, comparison of different assays in the diagnosis, occurrence of CPV types in this region of India and ascertaining the host predisposing factors like breed, age, sex, vaccination history etc.

\section{Materials and Methods}

Sampling procedure and preparation of bacteria free filtrate (BFF)

This work was conducted over a period of three years (2013-2015). Faecal samples were collected from pups showing signs of AGE and transported to laboratory in transport medium made up of Earle's balanced salt solution (EBSS) with kanamycin (Invitrogen, USA). Samples were thoroughly emulsified in EBSS and centrifuged at low speed and supernatant was filtered through $0.45 \mu \mathrm{m}$ cellulose acetate filter (Nunc, Denmark). The bacteria free filtrate (BFF) was used for further testing. The history of each animal regarding age, sex, breed and vaccination was recorded. The faecal samples were collected with the consent of the owners.

\section{Haemagglutination and haemagglutination inhibition tests}

Each sample was tested for its HA activity using $1 \%$ swine red blood cells (RBC) in $0.2 \%$ bovine serum albumin-phosphate buffered saline (BSA-PBS) for $4 \mathrm{~h}$ at $4{ }^{\circ} \mathrm{C}$ in U bottom microtitre plate (Laxbro, India). Live attenuated CPV vaccine (kindly provided by Dr. Amit Balyan, Mathura) was used as positive control and PBS was used as negative control. The HA activity of each sample was further confirmed by haemagglutination inhibition (HI) test with anti CPV-2 monoclonal antibody (Mab) (Meridian Inc. via Gentix, India).

\section{Antigen capture - enzyme linked immunosorbent assay (ELISA)}

Monoclonal antibody based antigen capture ELISA was conducted as previously described (Kumar et al. 2010). Monoclonal antibody procured for HI test was used as a capture antibody and allowed to be attached on a flat bottom 96 well microtitre plate (Polysorb Nunc, Denmark). Empty sites of wells were blocked with PBS-BSA. Wells were washed three times with PBS-tween-20. One hundred $\mu 1$ BFF (1:2 dilution with PBSBSA) was dispensed in each well to detect the antigen. Live attenuated vaccine virus and standard diluent $(1 / 5$ of $1 \%$ BSA in PBS-tween20) were used as positive and negative antigen control. After washing, antiparvovirus IgG (raised in canine, VMRD Inc., USA) was used as detector antibody. After washing the bound detector antibodies were allowed to react with anti-canine $\mathrm{IgG}$, conjugated with horse radish peroxidase (HRPO) (Calbiochem, Merck, Germany). Ortho phenylenediamine dihydrochloride (OPD) (Thermo Fischer, USA) in substrate buffer was used as chromogen. Optical density (OD) was recorded using 492 nm filter with ELISA plate reader (Multiskan, via Thermo, India). The ratio of 2 or more in OD of sample and negative control (P/N ratio) was considered positive.

\section{Polymerase chain reaction (PCR)}

The deoxyribonucleic acid (DNA) was isolated from BFF using previously described phenol chloroform isoamyl alcohol method for faecal samples (Kumar et al. 2011). Isolated DNA was subjected to PCR using two VP2 gene specific primers (Pereira et al. 2000). One primer could amplify both CPV-2a and CPV-2b types with 681 base pairs (bp) amplicon, whereas the second primer could amplify CPV-2b only with 427 bp amplicon (Table 1). The CPV -2b amplicon was further used to differentiate of CPV-2b and CPV-2c via RE analysis and sequencing.

\section{Purification of PCR products}

The 427 bp amplicon (CPV-2b positive) was repeatedly multiplied in PCR and accumulated PCR product was obtained in $100 \mu \mathrm{l}$ reaction volumes. These PCR products were purified with PCR purification kit (Gene JET, Thermo, USA) as per manufacturer's instructions. Purified PCR products containing about 50 ng per $\mu 1$ DNA concentration and 260/280 ratio above 1.7 were used for further analysis. 
Table 1. Primers and polymerase chain reaction (PCR) conditions for diagnosis of canine parvovirus -2 (CPV-2).

\begin{tabular}{lccc}
\hline Name & Forward primer & Reverse primer & PCR conditions \\
\hline CPV-2ab & GAAGAGTGGTTG & CCTATATCACC & Denaturation $-94^{\circ} \mathrm{C} / 30 \mathrm{~s}$ \\
(Determine both & TAAATAATA & AAAGTTAGTAG & Annealing $-52{ }^{\circ} \mathrm{C} / 2 \mathrm{~min}$ \\
CPV 2a and 2b) & & & Extension $-72{ }^{\circ} \mathrm{C} / 2 \mathrm{~min}$ \\
\hline CPV-2b & CTTTAACCTTC & CATAGTTAAATT & Denaturation $-94^{\circ} \mathrm{C} / 30 \mathrm{~s}$ \\
$($ Determine CPV & CTGTAACAG & GGTTATCTAC & Annealing $-52^{\circ} \mathrm{C} / 2 \mathrm{~min}$ \\
type 2b/2c) & & & Extension $-72{ }^{\circ} \mathrm{C} / 2 \mathrm{~min}$ \\
\hline
\end{tabular}

Restriction endonuclease (RE) digestion analysis

Purified 427 bp PCR products were incubated with MBoII enzyme as per manufacture's instruction (Thermo Scientific, USA). After incubation for $2 \mathrm{~h}$ at $37^{\circ} \mathrm{C}$, each digested PCR product was run on $2.0 \%$ agarose gel and observed for cleavage of amplicon in $397 \mathrm{bp}$ with or without small $30 \mathrm{bp}$ band using a $100 \mathrm{bp}$ ladder.

Sequence analysis

Ten representative samples were submitted for sequencing on a commercial basis (Agri Genome, India). Sequencing data were aligned with previously submitted sequences from India, vaccine strain and few other strains prevalent worldwide for homology determination (Table 2). The above nucleotide and translated amino acid sequences were aligned with our sequences in clustal algorithm of Mega 7.0 software (Kumar et al. 2016).

Table 2. Name and accession number of different canine parvovirus-2 (CPV-2) gene sequences used for comparison of sequences in the present study.

\begin{tabular}{|c|c|c|c|}
\hline $\begin{array}{l}\text { Serial } \\
\text { number }\end{array}$ & $\begin{array}{c}\text { Sequence } \\
\text { designation }\end{array}$ & $\begin{array}{l}\text { Accession } \\
\text { number }\end{array}$ & $\begin{array}{c}\text { Place } \\
\text { (Indian state/Country) }\end{array}$ \\
\hline 1 & CPV-2b & HQ259076 & Tamilnadu, India \\
\hline 2 & CPV-2b & HG004610 & Himachal Pradesh, India \\
\hline 3 & $\mathrm{CPV}-2 \mathrm{~b} / 2 \mathrm{c}$ & KC479136 & Uttar Pradesh (UP-9), India \\
\hline 4 & Partial VP2* & JF900762 & Kerala, India \\
\hline 5 & Partial VP2 & JN008397 & Tamilnadu, India \\
\hline 6 & Partial VP2 & KP071946 & Andhra Pradesh, India \\
\hline 7 & Partial VP2 & KР071956 & Andhra Pradesh, India \\
\hline 8 & Partial VP2 & KU866420 & Tamilnadu, India \\
\hline 9 & Complete VP2 & KP071954 & Punjab, India \\
\hline 10 & CPV-2b/2c & KC479137 & Uttar Pradesh (UP-10, India) \\
\hline 11 & CPV-2a and CPV-2b & M74849 & United States (USA) \\
\hline 12 & Complete VP2 & FJ005261 & Italy \\
\hline 13 & $\mathrm{NS} 1 * *+\mathrm{NS} 2+\mathrm{VP} 1+\mathrm{VP} 2$ & JX660690 & China \\
\hline 14 & Feline panleukopaenia virus & EU252147.1 & Korea \\
\hline
\end{tabular}

*. VP 2 = Viral protein 2 and **. NS = Non structural (proteins)

Determination of canine coronavirus and canine rotavirus as other possible agents

We also used CPV rapid immunochromatography test (Bio-note, Korea) as per manufacturer's instruction. All the CPV negative samples were further screened for canine coronavirus with rapid immunochromatography and negative samples in both screening procedures were searched for rotavirus via ribonucleic acid - polyacrylamide gel electrophoresis (RNA-PAGE ) (Laemmli 1970).

\section{Results}

A total of 73 samples were received or collected from the Surat and Navsari districts of the South Gujarat region. Of them 32, 33, and 35 were found positive for CPV-2 via HA, ELISA and PCR, respectively. As rapid test was included one year later, 26/52 samples 
were found positive in this test format (Table 3). Considering PCR as the most sensitive and specific test (Mochizuki et al. 1993), the prevalence of CPV-2 was found to be $47.94 \%$.

Table 3. Results of different tests for canine parvovirus-2 (CPV-2) diagnosis.

\begin{tabular}{llcccc}
\hline $\begin{array}{l}\text { Serial } \\
\text { number }\end{array}$ & \multicolumn{1}{c}{ Name of test } & \multicolumn{3}{c}{ Positive / Number } & \\
\hline 1 & Haemagglutination test & Year 2013 & Year 2014 & Year 2015 & Total \\
\hline 2 & Rapid immuno chromatography test & $7 / 16$ & $9 / 21$ & $16 / 36$ & $32 / 73$ \\
3 & Enzyme linked immunosorbent assay & $7 / 16$ & $8 / 21$ & $18 / 36$ & $33 / 73$ \\
4 & Polymerase chain reaction & $7 / 16$ & $10 / 21$ & $18 / 36$ & $35 / 73$ \\
\hline
\end{tabular}

This condition was found to be more common in females than males but the difference was not significant. Pups between 4-12 weeks of age are more prone to this infection. All but one samples were received from non-vaccinated animals. Regarding breed disposition, the Labrador was found to be the most predisposed breed to this condition (13 cases) followed by Pomeranian (5), Lhasa Apso (2), Cocker Spaniel (2) and others (13) including non-descript breeds (4) (Table 4). Among the other viral causative agents, 7 samples had $\mathrm{CCV}$, whereas rotavirus was not detected in any of the samples.

Table 4. Predisposing factors for canine parvovirus-2 (CPV-2) infection.

\begin{tabular}{|c|c|c|c|c|c|}
\hline \multirow[t]{2}{*}{ Observations } & \multirow[t]{2}{*}{ Categories } & \multicolumn{3}{|c|}{ Positive / Number } & \multirow[b]{2}{*}{ Total } \\
\hline & & Year 2013 & Year 2014 & Year 2015 & \\
\hline \multirow{2}{*}{$\begin{array}{l}\text { Sex of animal } \\
(P=0.4746) \\
\text { Non-significant }\end{array}$} & Male & $4 / 11$ & $4 / 13$ & $13 / 23$ & $21 / 47$ \\
\hline & Female & $3 / 5$ & $6 / 8$ & $5 / 13$ & $14 / 26$ \\
\hline \multirow[t]{6}{*}{ Age group } & 0-4 weeks & 0 & $0 / 0$ & $0 / 4$ & $0 / 4$ \\
\hline & 4-8 weeks & $2 / 6$ & $4 / 6$ & $5 / 12$ & $11 / 24$ \\
\hline & 8-12 weeks & $2 / 3$ & $4 / 6$ & $7 / 12$ & $13 / 21$ \\
\hline & $12-16$ weeks & $2 / 2$ & $1 / 4$ & $2 / 2$ & $5 / 8$ \\
\hline & Above16 weeks & $1 / 5$ & $1 / 4$ & $4 / 6$ & $6 / 15$ \\
\hline & Unavailable & $0 / 0$ & $0 / 1$ & $0 / 0$ & $0 / 1$ \\
\hline \multirow[t]{4}{*}{ Vaccination history } & Primary & $0 / 1$ & 0 & $1 / 1$ & $1 / 2$ \\
\hline & Complete & $0 / 1$ & 0 & 0 & $0 / 1$ \\
\hline & Unvaccinated & $7 / 10$ & $10 / 21$ & $17 / 35$ & $34 / 66$ \\
\hline & Not available & $0 / 4$ & $0 / 0$ & $0 / 0$ & $0 / 4$ \\
\hline
\end{tabular}

Out of 35 PCR positive samples, only 3 belonged to type CPV-2a and the remaining 32 showed positive amplicon of $427 \mathrm{bp}$ indicating they might belong to type CPV-2b or its mutant or 2c (Fig. 1-A). Therefore, a few samples $(n=10)$ were subjected to restriction endonuclease profiling and sequencing. The absence of $387 \mathrm{bp}$ product in $\mathrm{RE}$ profiling confirmed these isolates were negative for type CPV-2c (Fig. 1-B). These results were further validated by sequence analysis which confirmed them as type $2 \mathrm{~b}$ rather than type $2 \mathrm{c}$.

The sequences matched with submitted sequences of CPV-2b with $98-99 \%$ identity. When these were aligned with submitted Indian or foreign sequences, some major nucleotide differences were found at a different position, particularly with CPV-2a types. 

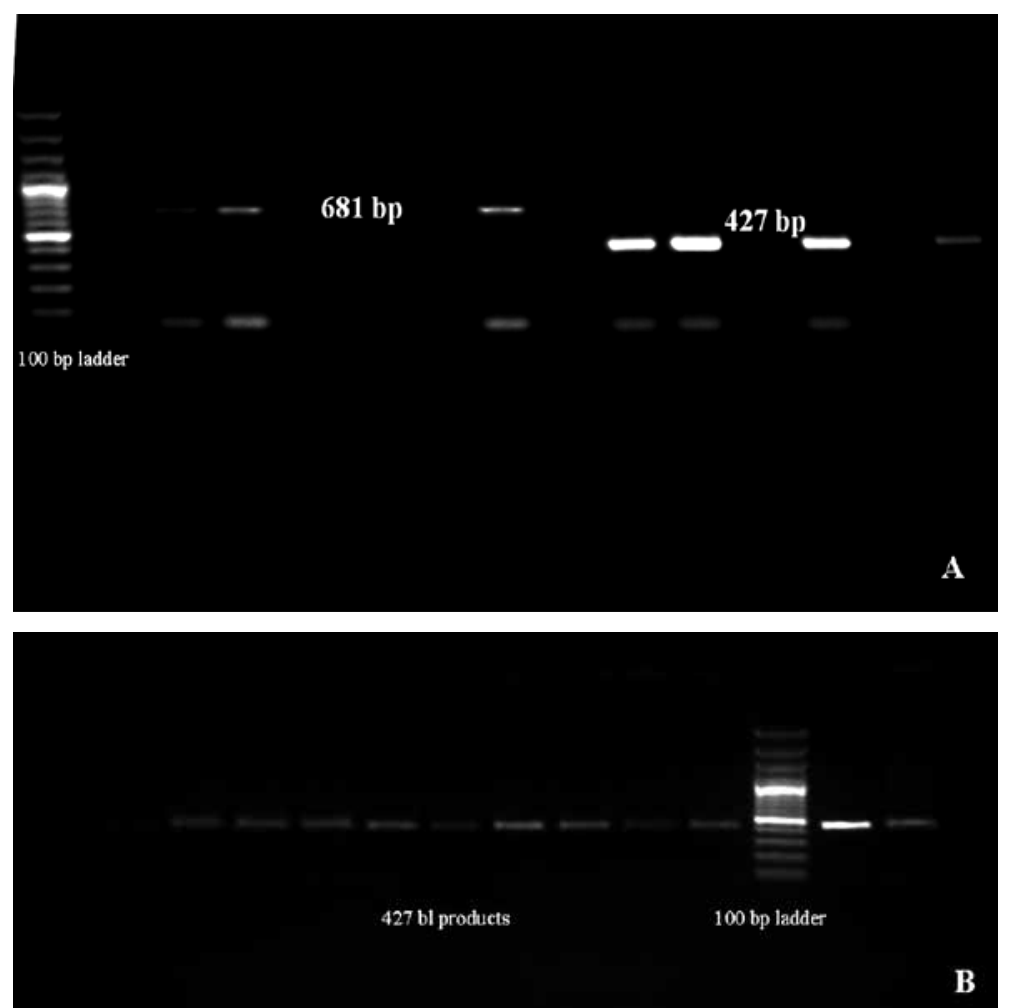

Fig. 1. Polymerase chain reaction (PCR) and restriction endonuclease (RE) analysis used for determination of canine parvovirus (CPV) types. (A) PCR showing amplicon of $681 \mathrm{bp}$ and $427 \mathrm{bp}$, showing positive test for CPV-2a /2b/2c and CPV-2b/2c, respectively. (B) RE analysis showing uncleaved band of 427 bp confirmed the absence of CPV-2c.

It showed that these were less distant to CPV-2b. Most importantly, based on a complete genome sequence ( $\mathrm{Ju}$ et al. 2012), a consistent nucleotide change was observed in $9 / 10$ sequences (except in isolate number-30) at position 4106 . This gave rise to one amino acid variation and generated threonine in the place of alanine. The difference was noted with the vaccine, the Italian strain, and the strains found in Indian states of Tamilnadu, Punjab (Ludhiana), Maharastra, Madhya Pradesh and Himachal Pradesh. The change was similar to the Chinese strain and the strains prevalent in Indian states of Uttar Pradesh and Madhya Pradesh (Plate V, Fig. 2). Recently, mutants having a similar nucleotide variation (with an additional variation) were designated as new CPV-2b.

\section{Discussion}

After its first reporting from India in 1982, CPV-2 has been reported from all over India (Nandi and Kumar 2010; Nookala et al. 2016). The present quantum of prevalence corresponds to earlier reports, where $41.50 \%$ (Parthiban et al. 2010), 49.00\% (Sharma et al. 2016), 53.12\% (Parthiban et al. 2012) and 53.90\% (Srinivas et al. 2013) cases of AGE were attributed to CPV-2 infection, whereas higher involvement of CPV-2, i.e. $60.46 \%$ (Kumar and Nandi 2010) and 63.00\% (Singh et al. 2014) was reported from 
the Uttar Pradesh province of India. The difference may be due to the sample size and area specific variation in host pathogen interactions, however, nearly half of the AGE cases were caused by CPV-2 in most reports.

In our work, rapid chromatography test showed the maximum of false positive and false negative reactions; otherwise, strong association was found between ELISA, HA, and PCR. The PCR was found marginally superior in organism detection compared to ELISA and HA. This notion was supported by other reports from India (Kumar et al. 2010) and abroad (Mochizuki et al. 1993). Contrary to earlier reports (Desario et al. 2005; Parthiban et al. 2012), different diagnostic assays did not show much disparity. In the latter study (Parthiban et al. 2012), HA was more efficient by detecting more cases $(22 / 53)$ than were detected by PCR (17/53) but HA positive and PCR negative samples were considered as false positive by authors. Strong correlation between conventional and molecular work was observed due to the small geographical coverage in sampling. Therefore, pathogen diversity might be virtually absent and hence all the positive samples were detected by the applied tests. Due to the advantages of PCR over HA and cell culture (Mochizuki et al. 1993), and uncertainty of results in rapid test, more and more workers have nowadays detected CPV-2 solely based on PCR (Chinchkar et al. 2006; Parthiban et al. 2010; Singh et al. 2014). The ELISA is also a suitable alternative (Rimmelzwaan et al. 1991; Kumar et al. 2010), but it cannot differentiate between types. In our experience, it also has to be standardised time to time.

The absence of CPV-2 cases among pups aged 0-4 weeks was due to the presence of maternal antibodies; maximum frequency of detection was found at 4-16 weeks of age. A similar notion has been described previously (Srinivas et al. 2013). Comparison of predisposition of different dog breeds to CPV infection has not been established but the German shepherd, Pomeranian, Doberman etc. have been reported as susceptible breeds (Houston et al. 1996; Nandi and Kumar 2010). In our study, negligible numbers of CPV-2 suspected cases in vaccinated animals were reported which was in agreement with previous studies (Srinivas et al. 2013; Kaur et al. 2014; Sharma et al. 2016). This fact was explained as that even the heterologous variants to vaccine strains can be protected by $\mathrm{CPV}-2 \mathrm{~b}$ vaccines. But, inclusion of newer homologous strains is advocated due to increased genotypic variation in pathogens and vaccine strains (Decaro et al. 2005; Decaro et al. 2007; Decaro et al. 2009).

The CCV and canine rotavirus have been considered as other major pathogens of canine diarrhoea (Rimmelzwaan et al. 1991). The present work also showed that CCV is another major cause of AGE in pups and warrants to carry out more studies on CCV and other causative agents of this syndrome.

Our study found that CPV-2b is a prevalent strain in this area. Previously, the dominance of CPV-2b over CPV-2a was supported by other researchers (Parthibhan et al. 2012; Srinivas et al. 2013; Nookala et al. 2016; Sharma et al. 2016). In most of the studies covering small regions, the dominance of one strain over the other shows that they are mutually exclusive. We expected the emergence of CPV-2c because of earlier reports from India (Nandi et al. 2010), however, we did not detect it. Corroborating our data, recent reports on CPV from different parts of India (Parthibhan et al. 2012; Srinivas et al. 2013; Kaur et al. 2014; Nookala et al. 2016; Sharma et al. 2016) indicate the absence or very low prevalence (Kaur et al. 2014; Nookala et al. 2016) of CPV-2c. It is likely that after the first wave of infection, CPV-2c has limited its niche in India.

The strategy used in the present work for type differentiation was based on the PCR (Pereira et al. 2000) and due to the accumulation of recent mutations in the VP2 gene (Decaro and Buonavogalia 2012; Nookala et al. 2016), this strategy has some limitations (Martella et al. 2006). Therefore, $427 \mathrm{bp}$ amplicon of few samples $(\mathrm{n}=10)$ was sequenced in both forward and reverse orientation whereby occurrence of mutation at 4062-4064 
(CPV-2c), 4015-4016 (new CPV-2b) and 4449-4451 (new CPV-2a) could be determined. No change could be discerned at the nucleotide position 4449-4451 to determine CPV-2a and CPV-2b. The sequencing analysis results revealed that these isolates belonged to a novel mutant of new CPV-2b. Considering the rapid dynamics of this pathogen, the occurrence of novel CPV-2a and CPV $2 b$ types have already been emphasized by researchers from India (Srinivas et al. 2013; Nookala et al. 2016). But in the present work, new CPV-2b is predominating rather than new CPV-2a of those earlier reports. The quantum of change (9/10 sequences) showed the replacement potential of these strains to prototypic CPV-2b and CPV-2a strains. The most important change observed was the change from presently employed classical CPV-2 type of vaccines in India. Two amino acid variations have been described in CPV-2b which give rise to new CPV-2b strain (Srinivas et al. 2013), first as serine to alanine (at 3675-3677) and other as threonine to alanine. The first variation was not included in the PCR product length but the second one was consistently found. It is noteworthy from the epidemiological point of view that the latter variation is located near the nucleotide position (3676-4062) (Reed et al. 1988), which determines the receptor range of the virus (Srinivas et al. 2013) and increased pathogenicity (Ju et al. 2012).

\section{Conflict of Interest}

The authors declare that no conflict of interests lies among them.

\section{Acknowledgements}

Authors are profoundly thankful to Dr. Vipin Deshmukh for submitting the samples for the study, Dr. Amit Balyan for providing the CPV-2 live vaccine and the Dean, Veterinary College, NAU, Navsari for providing the financial support.

\section{References}

Amrani N, Desario C, Kadiri A, Cavalli A, Berrada J, Zro K, Sebbar G, Colaianni ML, Parisi A, Elia G, Buonavoglia C, Malik J, Decaro N 2016: Molecular epidemiology of canine parvovirus in Morocco. Infect Genet Evol 41: 201-206

Buonavoglia CV, Martella A, Pratelli M, Tempesta A, Cavalli D, Bozzo G, Decaro N, Carmichael LE 2001: Evidence for evolution of canine parvovirus type-2 in Italy. J Gen Virol 82: 1555-1560

Chinchkar S, Subramanian BM, Rao HN, Rangarajan PN, Thiagarajan D, Srinivasan VA 2006: Analysis of VP2 gene sequences of canine parvovirus isolates in India. Arch Virol 151: 1881-1888

Decaro N, Campolo M, Desario C, Elia G, Martella V, Ricci D, Lorusso E, Buonavoglia C 2005: Maternallyderived antibodies in pups and protection from canine parvovirus infection. Biologicals 33: 261-267

Decaro N, Desario C, Elia G, Campolo M, Lorusso M, Mari V, Martella V, Buonavoglia C 2007: Occurrence of severe gastroenteritis in pups after canine parvovirus vaccine administration: a clinical and laboratory diagnostic dilemma. Vaccine 25 : 1161-1166

Decaro N, Cirone F, Desario C, Elia G, Lorusso E, Colaianni ML, Martella V, Buonavoglia C 2009: Severe parvovirus in a 12-year-old dog that had been repeatedly vaccinated. Vet Rec 164: 593-595

Decaro N, Desario C, Beall MJ, Cavalli A, Campolo A, Dimarco AA, Amorisco F, Colaianni ML, Buonavoglia C 2010: Detection of canine parvovirus type 2 c by a commercially available in-house rapid test. Vet J 184: 373-375

Decaro N, Buonavoglia C 2012: Canine parvovirus - A review of epidemiological and diagnostic aspects, with emphasis on type 2c. Vet Microbiol 155: 1-12

Decaro N, Desario C, Billi M, Lorusso E, Colaianni ML, Colao V, Elia G, Ventrella G, Kusi I, Bo S, Buonavoglia C 2013: Evaluation of an in-clinic assay for the diagnosis of canine parvovirus. Vet J 198: 504-507

Decaro N, Buonavoglia C 2017: Canine parvovirus post-vaccination shedding: Interference with diagnostic assays and correlation with host immune status. Vet J 221: 23-24

Desario C, Decaro N, Campolo M, Cavalli A, Cirone F, Elia G, Martella V, Lorusso E, Camero M, Buonavoglia C 2005: Canine parvovirus infection: which diagnostic test for virus? J Virol Methods 126: 179-185

Dowgier G, Lorusso E, Decaro N, Desario C, Mari V, Lucente MS, Lanave G, Buonavoglia C, Elia G 2017 : A molecular survey for selected viral enteropathogens revealed a limited role of canine circovirus in the development of canine acute gastroenteritis. Vet Microbiol 204: 54-58

Filipov C, Desario C, Patouchas O, Eftimov P, Gruichev G, Manov V, Filipov G, Buonavoglia C, Decaro N 2016: A ten-year molecular survey on parvoviruses infecting carnivores in Bulgaria. Transbound Emerg Dis 63: $460-464$ 
Houston DM, Ribble CS, Lead LL 1996: Risk factors associated with parvovirus enteritis in the canine parvovirus of dogs. J Am Vet Med Assoc 208: 542-548

Ju C, Cheng Y, Ji Y, Wang Y, Sun L, Huang J 2012: Genome sequence of canine parvovirus strain SC02/2011, isolated from a puppy with severe diarrhea in south China. J Virol 86: 13805

Kaur G, Chandra M, Dwivedi PN, Sharma NS 2014: Antigenic typing of canine parvovirus using differential PCR. Virus Dis 25: 481-487

Kumar M, Chidri S, Nandi S 2011: A sensitive method to detect canine parvoviral DNA in faecal samples by nested polymerase chain reaction. Indian J Biotechnol 10: 183-187

Kumar M, Nandi S 2010: Molecular typing of canine parvovirus variants by polymerase chain reaction and restriction enzyme analysis. Transbound Emerg Dis 57: 458-463

Kumar M, Nandi S, Chidri S 2010: Development of a polyclonal antibody-based AC-ELISA and its comparison with PCR for diagnosis of canine parvovirus infection. Virol Sin 25: 352-360

Kumar S, Stecher G, Tamura K 2016: MEGA7: Molecular evolutionary genetics analysis version 7.0 for bigger datasets. Mol Biol Evol 33: 1870-1874

Laemmli UK 1970: Cleavage of structural proteins during the assembly of the head of bacteriophage T4. Nature 227: 680-685

Martella V, Decaro N, Elia G, Buonavoglia C 2005: Surveillance activity for canine parvovirus in Italy. J Vet Med B 52: 312-315

Martella V, Decaro N, Buonavoglia C 2006: Genetic and antigenic variation of CPV-2 and implication for antigenic/genetic characterization. Virus Genes 33: 11-13

Mira F, Purpari G, Lorusso E, Di Bella S, Gucciardi F, Desario C, Macaluso G, Decaro N, Guercio A 2018 : Introduction of Asian canine parvovirus in Europe through dog importation. Transbound Emerg Dis 65: 16-21

Mochizuki M, SanGabriel MC, Nakatani H, Yoshida M, Harasawa R 1993: Comparison of polymerase chain reaction with virus isolation and haemagglutination assays for the detection of canine parvoviruses in faecal specimens. Res Vet Sc 55: 60-63

Nandi S, Chidri S, Kumar M, Chauhan RS 2010: Occurrence of canine parvovirus type 2c in the dogs with haemorrhagic enteritis in India. Res Vet Sci 88: 169-171

Nandi S, Kumar M 2010: Canine parvovirus: Current perspective. Indian J Virol 21: 31-44

Nookala M, Mukhopadhyay HK, Sivaprakasam A, Balasubramanian B, Prabhakar XA, Thanislass J, Srinivas MV, Pillai RM 2016: Full-length VP2 gene analysis of canine parvovirus reveals emergence of newer variants in India. Acta Microbiol Immunol Hung 63: 411-426

Parrish CR, Aquadro CF, Carmichael LE 1988: Canine host range and a specific epitope map along with variant sequences in the capsid protein gene of canine parvovirus and related feline, mink, and raccoon parvoviruses. Virology 16: 293-307

Parthiban S, Mukhopadhyay HK, Antony PX, Pillai RM 2010: Molecular typing of canine parvovirus occurring in Pondicherry by Multiplex PCR and PCR-RFLP. Indian J Virol 21: 86-89

Parthiban M, Saranya R, Divya KC, Kumanan K 2012: Detection of antigenic variation of canine parvovirus strains of Tamilnadu using differential PCR. Indian J Anim Sc 82: 237-239

Pereira CA, Monezi TA, Mehnert DU, D’Angelo M, Durigon EL 2000: Molecular characterization of canine parvovirus in Brazil by polymerase chain reaction assay. Vet Microbiol 75: 127-133

Reed AP, Jones EV, Miller TJ 1988: Nucleotide sequence and genome organization of canine parvovirus. J Virol 62: $266-276$

Rimmelzwaan GF, Groen J, Egberink H, Borst GHA, UytdeHaag FGCM, Osterhaus ADME 1991: The use of enzyme-linked immunosorbent assay systems for serology and antigen detection in parvovirus, corona virus and rota virus infections in dogs in Netherlands. Vet Microbiol 26: 25-40

Sharma S, Dhar P, Thakur A, Sharma V, Sharma M 2016: First detection of canine parvovirus type $2 b$ from diarrheic dogs in Himachal Pradesh. Vet World 9: 964-969

Singh D, Verma AK, Kumar A 2014: Phylogenetic analysis of canine parvovirus isolates from Mathura, India. Vet Arhiv 84: 505-512

Srinivas VMV, Mukhopadhyay HK, Thanislass J, Antony PX, Pillai RM 2013: Molecular epidemiology of canine parvovirus in southern India. Vet World 6: 744-749

Wu J, Gao XT, Hou, SH, Guo XY, Yang XS, Yuan WF, Xin T, Zhu HF, Jia H 2015: Molecular epidemiological and phylogenetic analyses of canine parvovirus in domestic dogs and cats in Beijing, 2010-2013. J Vet Med Sci 77: 1305-1310 
Plate V

Sharma K. et al.: Diagnosis and characterization ... pp. 247-254

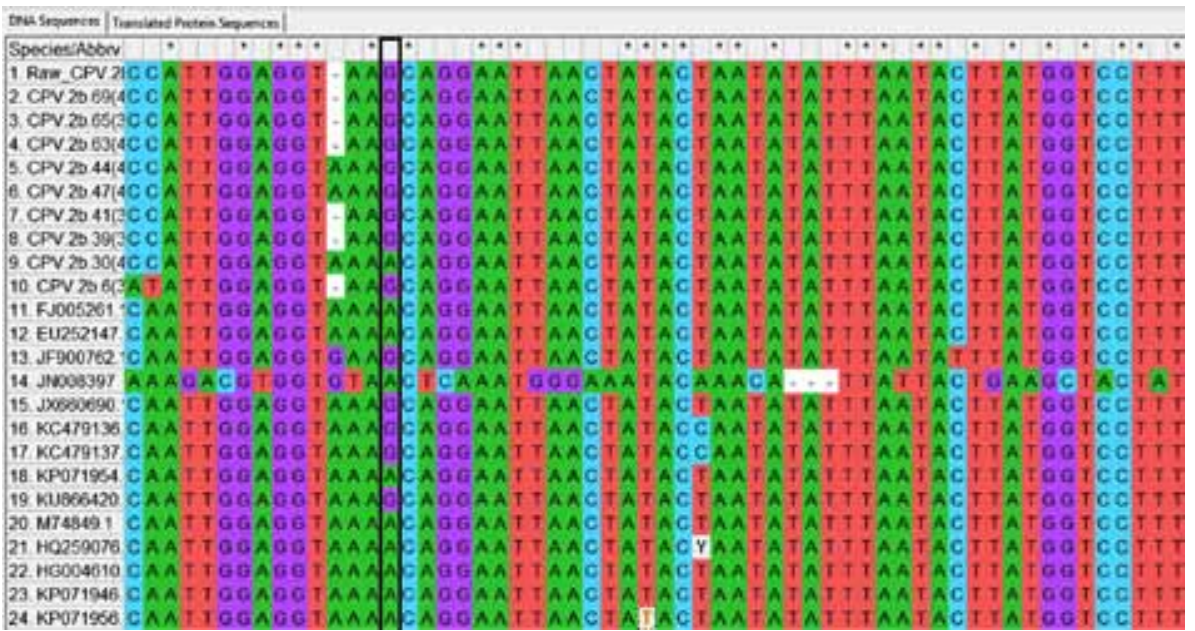

Fig. 2. Nucleotide sequencing of canine parvovirus-2b (CPV-2b) showing adenosine to guanosine (A-G) change at the 4106 position with square box. 